\title{
Determination of Elements in Acid Leaching of Graphite Using Instrumental Neutron Activation Analysis
}

\author{
Adel Fisli ${ }^{1}$, Deni Mustika ${ }^{2}$, Sudirman $^{1}$, Torowati $^{2}$, Th. Rina Mulyaningsih ${ }^{1}$, Arbi Dimyati $^{1}$, I Made Joni $^{3}$ \\ ${ }^{1}$ Center for Science and Technology of Advanced Material-National Nuclear Energy Agency (BATAN) Kawasan \\ Puspiptek, Serpong, Banten, Indonesia \\ ${ }^{2}$ Center for Nuclear Fuel Technology- National Nuclear Energy Agency (BATAN) Kawasan Puspiptek Serpong, Banten, \\ Indonesia \\ ${ }^{3}$ Nanotechnology and Graphene Research Center (NGRC) Directorate of Research and Community Development, \\ Padjajaran University, Bandung, Indonesia \\ Correspondence: Adel Fisli, Center for Science and Technology of Advanced Material-National Nuclear Energy Agency \\ (BATAN) Kawasan Puspiptek, Serpong, Banten, Indonesia. E-mail: adel@batan.go.id
}

Received: November 21, 2019 Accepted: December 16, 2019 Online Published: December 30,2019

doi:10.5539/ijc.v12n1p89

URL: https://doi.org/10.5539/ijc.v12n1p89

\begin{abstract}
Graphite material is extremely undissolvable to be turned into chemical solutions, therefore sample preparation is a serious problem faced in the determination of elemental impurity content in a graphite material. In this work, The nondestructive approach of instrumental neutron activation analysis (INAA) is applied to determine the concentration of multi-element in a graphite material, by employing both the forth floating process and the acid treatment method to the local Indonesian graphite. The sample was irradiated in the Rabbit system of G.A. Sywabessy Multi-Purpose Reactor at Serpong, Indonesia. The precision of the analysis was evaluated using certified reference materials which were obtained good performance with the most of concentration value in the range of $3<$ zheta score $<-3$. Eleven elemental $(\mathrm{Al}$, Sb, $\mathrm{Co}, \mathrm{Cu}, \mathrm{La}, \mathrm{Mn}, \mathrm{Sc}, \mathrm{Na}, \mathrm{W}, \mathrm{V}$, and $\mathrm{Zn}$ ) concentration were determined in the forth floating process of the graphite. The $\mathrm{Cu}$ elemental is the most content with the value of $60,8 \mathrm{mg} / \mathrm{kg}$ or about $90 \%$ of total concentration content in graphite. Followed by the $\mathrm{Sb}$ content with a value of $5,5 \mathrm{mg} / \mathrm{kg}$ (about $8 \%$ of total impurities content in graphite). The remaining $2 \%$ includes the intermediate and the minor content of other impurity elements. After the acid treatment, the total concentration of impurities contained in the graphite material drastically decreases from $6.7 \%$ w/w to about 0,$1 ; 0.6$; and $0.59 \% \mathrm{w} / \mathrm{w}$ for treatment employing the $\mathrm{HF}, \mathrm{HNO}_{3}+\mathrm{H}_{2} \mathrm{SO}_{4}$, and $\mathrm{HF}+\mathrm{HCl}+\mathrm{H}_{2} \mathrm{SO}_{4}$ acid reagent, respectively. $\mathrm{Cu}$ element makes the largest contribution to reduce the concentration of impurities in graphite which decreased from 60,675 $\mathrm{mg} / \mathrm{kg}$ to $1,088 \mathrm{mg} / \mathrm{kg} ; 925 \mathrm{mg} / \mathrm{kg}$ and $835 \mathrm{mg} / \mathrm{kg}$ for $\mathrm{HF}, \mathrm{HNO}_{3}+\mathrm{H}_{2} \mathrm{SO}_{4}$ and $\mathrm{HF}+\mathrm{HCl}+\mathrm{H}_{2} \mathrm{SO}_{4}$ acid reagent, respectively. In addition, $\mathrm{Sb}$ element concentration dropped dramatically from $5,514 \mathrm{mg} / \mathrm{kg}$ to $93 \mathrm{mg} / \mathrm{kg}$ using HF reagents. The other trace elements ( $\mathrm{As}, \mathrm{Ba}, \mathrm{Ca}, \mathrm{Ce}, \mathrm{Eu}, \mathrm{Fe}, \mathrm{Mg}, \mathrm{Sm}$, and $\mathrm{Th}$ ) were also identified in the acid reagent treated graphite sample which are suspected to derivates from the impurity reagent and or from contamination during the sample preparation. The treated HF for graphite was obtained the low purity grades approach for nuclear graphite.
\end{abstract}

Keywords: graphite, nuclear material, INAA, acid leaching, element determination

\section{Introduction}

Graphite which is a naturally occurring crystal carbon polymorphs is composed of a series of stacked parallel layer planes of the carbon structure. Graphite has been widely used in many application in various fields, such as metallurgy and semiconductor process, electrical, automobile industry, alkaline batteries, electric conductors and industry electrodes (Pierson 1993). Furthermore, graphite has good mechanical performances, thermal properties, resistant to irradiation and chemical attack, making it an excellent material for advanced application such as nuclear structural components. Graphite was used in structural components supporting the reactor core in the Advanced Gas-cooled Reactors (AGRs) and High-Temperature Gas-cooled Reactors (HTGRs) as moderator, reflector and fuel matrix (Zhou et al. 2017).

Information concerning the content of trace elements in graphite is very important to evaluate its suitability in the application. High purity graphite was needed for nuclear applications and semiconductor components. Some contaminants even at trace element contents could have a negative effect on its application (Pierson 1993). The presence 
of impurities elements can cause an increase of the oxidation rate of carbon graphite, such as; $\mathrm{Pb}, \mathrm{Bi}$ (very strong accelerators), $\mathrm{Li}, \mathrm{Na}, \mathrm{K}, \mathrm{V}, \mathrm{Mn}, \mathrm{Co}, \mathrm{Cu}, \mathrm{Ag}$ (strong accelerators) and $\mathrm{Mg}, \mathrm{Al}, \mathrm{Si}, \mathrm{S}, \mathrm{Ca}, \mathrm{Ti}, \mathrm{Cr}, \mathrm{Fe}, \mathrm{Ni}, \mathrm{Zn}, \mathrm{Sr}, \mathrm{Zr}, \mathrm{Mo}$, $\mathrm{Ba}$ (weak to moderate accelerators) (Maahs and Schryer 1967). High purity nuclear grade graphite requires a maximum total impurity of $300 \mathrm{mg} / \mathrm{kg}$, and low purity grades are allowed a maximum total impurity level of $1000 \mathrm{mg} / \mathrm{kg}$ (Windes et al. 2014). The other impurity elements which need to be avoided in the nuclear grade graphite are those elements having a large neutron absorption cross-section such as B, Cd, and some rare earth element ( $\mathrm{Sm}, \mathrm{Eu}, \mathrm{Gd}, \mathrm{Dy}, \mathrm{Er}, \mathrm{Yb}, \mathrm{Ce}$, Th) (Sadanandam and Sharma 2016). Those listed elements could have a significant negative impact on neutron flux. The equivalent boron content of $\leq 5 \mathrm{mg} / \mathrm{kg}$ on graphite is allowed for application as fuel element of the HTTR (IAEA 2012).

Graphite is a naturally occurring material, which in its natural or original state would contain constituents' impurities in either organic, inorganic form or a combination of both the organic and the inorganic impurity. The content of impurities in graphite is in the range of percentages detectable to the tracer. Therefore, to obtain high quality graphite, a process is needed to separate the impurities from the graphite structure. There are various methods for purifying graphite, generally divided into two kinds, namely; physical purification (including froth floating method and high-temperature method) and chemical purification (including chlorination roasting method and acid-base treatment method). The froth floating is a process separation based on a polarity difference of mixture material. The hydrophobic material (graphite) can be separated from hydrophilic material (its oxide mineral impurities) using certain reagents (Florena et al. 2016). The natural graphite is usually given the heat treatment temperatures above $2800^{\circ} \mathrm{C}$ to $3000^{\circ} \mathrm{C}$ in a furnace under inert environment for about four to five weeks. In this step, the impurities in natural graphite reduced and vaporized (Robert 2007). During the chemical purification process, the natural graphite was treated with alkaline and acid (hydrochloric, hydrofluoric, sulfuric and nitric). The impurities react with the strong acids before dissolving (Arachchi et al. 2017). The ability to dissolve impurities depends on chemical reagent, impurities type and affinity (Robert 2007).

The determination of elemental impurities in graphite is not as simple as the other widely used method. The main problem one faced is related to the preparation step of the sample. Graphite material is extremely difficult to turn into a solution due to its stable structure (Pierson 1993). Graphite is hardly dissolved using the conventional acids digestion method even when combined with a temperature and pressure condition (Suzuki, Miyatani, and Yoshimoto 1993). Several methods have been attempted to determine the multi-element in graphite through chemical dissolution such as microwave-induced synchrotron radiation based X-ray fluorescence spectrometry (Ghosh et al. 2017), microwave-induced combustion method with ICP-OES and ICP-MS (Mesko et al. 2010)(Cruz et al. 2015). However, this procedure takes a comparatively longer time to complete, and the high volume of concentrated acid is needed for a complete digestion (Hashitani et al. 1986).

Some authors have used the non-destruction methods (without chemical dissolution of sample) to determine the trace elements in graphites such as direct solid sampling electrothermal atomic Absorption spectrometry (ETAAS) (Schaffer and Krivan 2001), X-ray Fluorescence (XRF) Spectrometry (Obi 1990), energy dispersive X-ray fluorescence (EDXRF) (Natarajan et al. 2010), laser-ablation inductively coupled plasma mass spectrometry (LA-ICP-MS) (Pickhardt and Becker 2001), direct atomic absorption spectrometry (DAAS) (Zacharia et al. 2007). However, the results are not yet satisfactory because these methods still have some form of constraints which limit their performance in determining the trace elements.

It is known that instrumental neutron activation analysis (INAA) is a versatile, sensitive, multi-element analytical technique with a very low detection limit for both qualitative and quantitative analysis. INAA method is not necessary destructive to the sample (non-destructive method), so all problems related to the decomposition of the sample and separation (dissolution, contamination and loses) could be avoided. This aspect is a powerful technique for materials that are difficult to dissolve e.g., geological samples (Mohammadzadeh et al. 2018), archaeological ceramics (Santos et al. 2006) silicon (Chu et al. 1990) and carbon material. Fortunately, the graphite is composed of the carbon element which hardly forms any radioactive isotopes; therefore, the influence of the matrix is negligible. This reason makes the method highly sensitive for measuring trace elements (Witkowska, Szczepaniak, and Biziuk 2005). It was reported that the trace elements contents were successfully determined in natural, nuclear grade, commercial graphite sample by INAA (Jerzy Janczyszyn and Kwiecinska 2015) (Shinde, Acharya, and Verma 2012). In the previous study, the authors have first purified the natural graphite of Indonesia using the appropriate type of acid leaching, followed by physical characterization of the sample employing a variety of methods (Mustika et al. 2019). Further, in this work, the authors have focused their objective on the determination of the multi-element contents in the forth floating process and treated acid of local Indonesia graphite using instrumental Neutron Activation Analysis (INAA). 


\section{Method}

\subsection{Purification Process of Graphites}

The graphite ore samples were collected from West Kalimantan Indonesia. The graphite was isolated from its ore by froth flotation process from the other gangue mineral (Joni et al. 2013). Purification processes of graphitewere done according to Mustika et al. (Mustika et al. 2019); typically, the isolated graphite was leached by $\mathrm{HF}, \mathrm{H}_{2} \mathrm{SO}_{4}+\mathrm{HNO}_{3}(1: 1)$ and $\mathrm{HF}+\mathrm{HCl}+\mathrm{H}_{2} \mathrm{SO}_{4}(1: 1: 1)$ solution at 1:5 weight ratio. The mixture was stirred for 3 hours and washed by aquadest for several times until it reaches the neutral level $\mathrm{pH}$ of supernatant. The purified graphite was dried at $115^{\circ} \mathrm{C}$ in the oven and further crushed.

\subsection{Sample preparation, Irradiation and Counting}

The graphite samples powder was homogenized and then oven-dried at $60^{\circ} \mathrm{C}$. An amount of 50-100 mg of sample and reference material were precision weighted using a high-precision balance and then packed in a vial polyethylene. Two replicats of each samples were prepared. Standard reference material of coal fly ash 1633b from National Institute of Standards and Technology (NIST) and flux monitor of Al-0,1\% Au from IRRM (Institutefor Reference Material and Measurement) were prepared and irradiated together with the samples. The reference materials were used as a comparator standard for gamma spectrum evaluation using the relative method of standardization for neutron activation analysis (NAA) and to check for the accuracy of the analytical method used for k0-INAA (Mulyaningsih and Yusuf 2018).

Two samples together with the standard sample packed in a polyethylene container were irradiated for 15 seconds. Irradiation were carried out in Rabbyt system of G.A. Sywabessy Multy Purpose Reactor at Serpong, at a neutron flux of $\sim 10^{13} \mathrm{n} \mathrm{cm}^{-2} \mathrm{~s}^{-1}$. After a period of time of 5 minutes and 15 minutes cooling, the irradiated samples and standard were measured by high purity germanium detector from Canbbera. Graphite sample were packed in vial polyethylene and aluminium foil for medium and long irradiation. Samples together with standard and flux monitor Al-0,1\% Au from IRRM packed in aluminium container were irradiated for a period of 10 min (medium irradiation) and $3 \mathrm{~h}$ (long irradiation). After a period oftime of 2 days (for medium irradiation) and 10 days cooling (long irradiation), the irradiated samples, standard and flux monitor were measured by high purity germanium detector (Canberra) with 1.8 $\mathrm{keV}$ of resolution for $1332 \mathrm{keV}$ of Co-60 and $25 \%$ relative efficiency. The spectra were evaluated with the program Genie 2000 software version 3.2. Quantytative analysis was carried out by comparative- INAA procedure for short half live radionuclide and ko-INAA method for medium and long half live radionuclide.

\section{Result and Discussion}

In order to check the reliability of the method, the precision and accuracy of the results were evaluated by analyzing the standard reference material NIST-SRM 1633b Coal Fly Ash. Figure 1 shows the gamma-ray spectrum of NIST-SRM 1633b Coal Fly Ash. The 18 of elements can be evaluated utilizing the so-called proficiency test of method. This material was chosen due to the similarity of its matrix to the matrix of graphite. This standard material was appropriated from each batch of the sample to be analyzed. The analytical result was evaluated by the zeta-score (Table 1) which was calculated based on the defined value given by SRM 1633b coal fly ash.

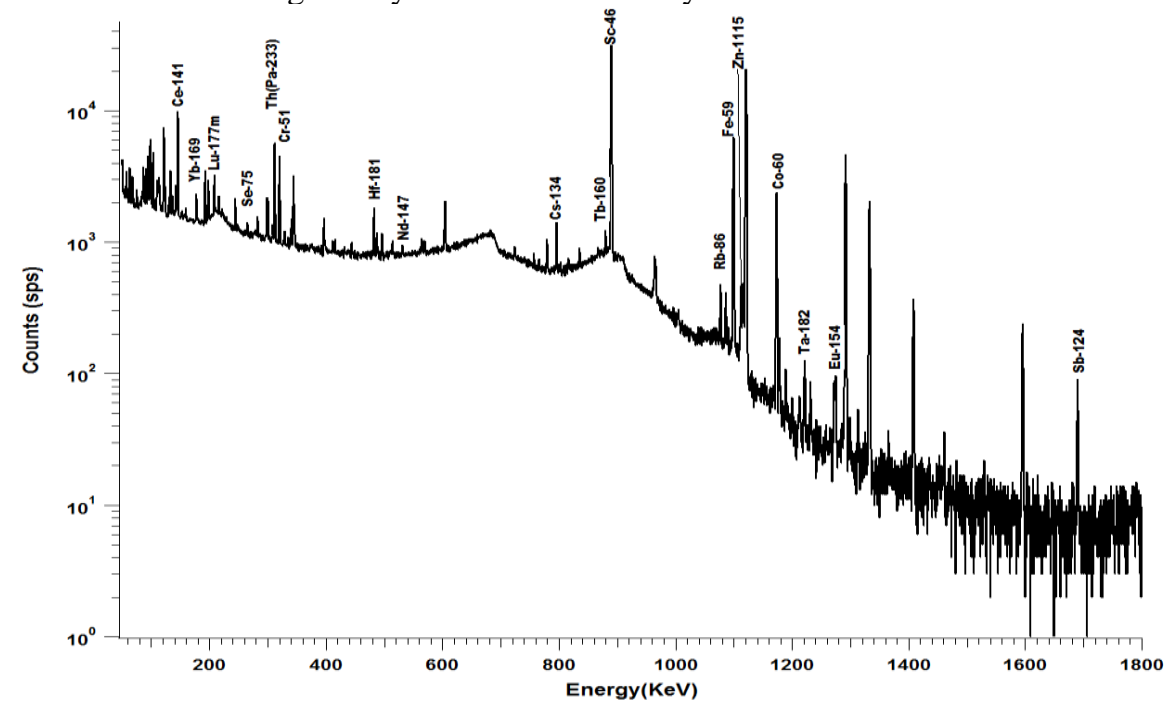

Figure 1. Gamma-ray spectrum of NIST-SRM 1633b coal fly ash 
Table 1. The acceptance criteria for U-test (Sutisna et al. 2017)

\begin{tabular}{ll}
\hline $\mathrm{U} \leq 1.64$ & The reported result does not differ from the assigned values \\
\hline $1.64 \leq \mathrm{U} \leq 1.95$ & The reported result probably does not differ from an assigned value \\
\hline $1.95 \leq \mathrm{U} \leq 2.58$ & It is not clear whether the reported value and assigned value differ. \\
\hline $2.58 \leq \mathrm{U} \leq 3.29$ & The reported result is probably different from an assigned value \\
\hline $3.29 \leq \mathrm{U}$ & The reported result does not differ from the assigned values \\
\hline
\end{tabular}

The accuracy, precision and zheta-score value are shown in Figure 2. The results show that most elements in coal fly ash were in a good agreement with the certified values. The majority of Z-score value was below 3, except for Hf, Cs and $\mathrm{Yb}$. The obtained data indicate the viability of using INAA. Z-score is frequently used to compare an observation to a standard normal deviate. They can be defined without assumptions of normality.

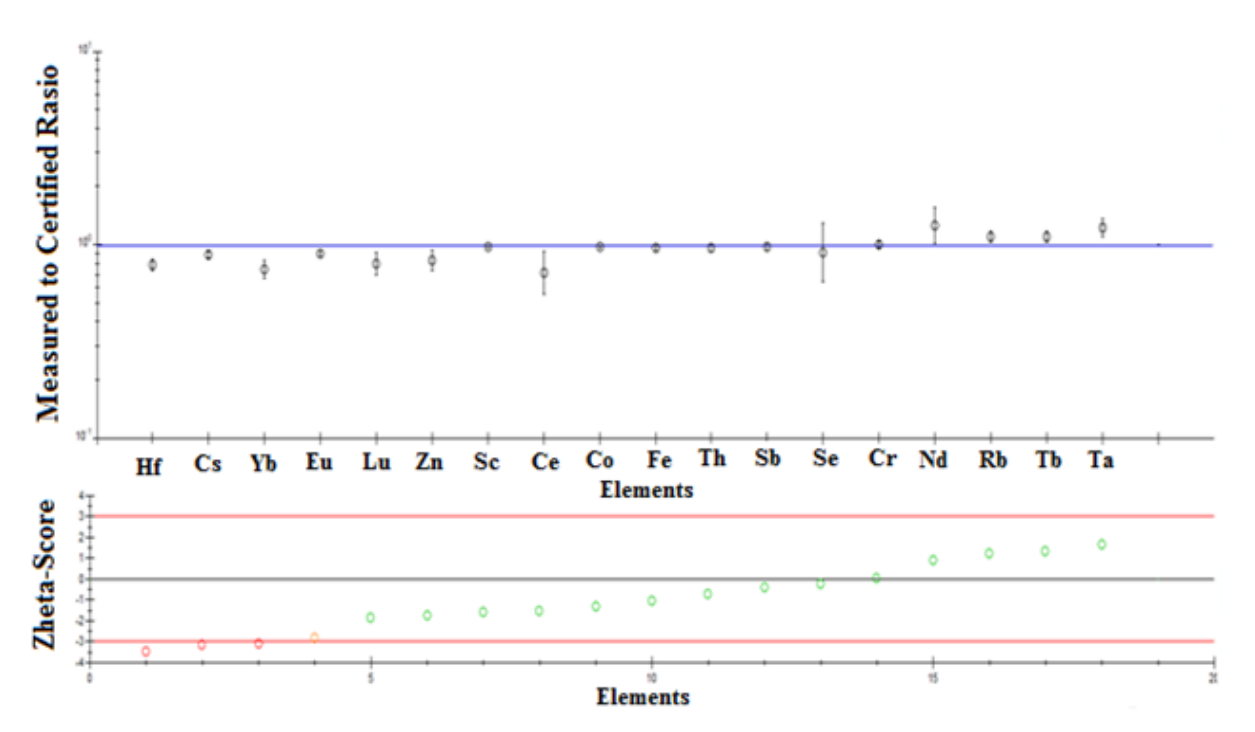

Figure 2. Internal Quality control using NIST -SRM 1633b coal fly ash

The sensitivity of INAA depends on nuclear parameters of the element, such as neutron cross-section, isotope, abundance, half-life, and gamma-ray abundance as well as available neutron flux, length of irradiation, detector efficiency, matrix composition and total sample size (Witkowska, Szczepaniak, and Biziuk 2005). The main objective of irradiation is to generate sufficient activity in the sample, taking into counting the decay time, to measure the gamma spectrum under ideal conditions. Short-lived nuclides were required for short irradiation and long-lived nuclides were required for long irradiation. The optimum decay time of a certain nuclide measurement depends on the half-life of that nuclide and on half-lives of the major spectral interferences (IAEA 1990).

Table 2 shows the nuclear parameters of elements (radionuclide, half-life, and gamma-ray) which have been successfully identified in the gamma-ray spectrum of the irradiated sample. It was shown that it possible for an element to produce the various radionuclides. The sign $(*)$ is the energy of gamma-rays which is used to quantitatively calculate a radionuclide. It was recommended in order to avoid interference originating from other radionuclides. 
Table 2. Nuclear parameters of element detected in the present work (IAEA 1990)

\begin{tabular}{cllll}
\hline No & Element & radionuclide & Half-life & $\gamma$-ray $(\mathrm{keV})$ \\
\hline 1 & Aluminium(Al) & Al-28 & $2.24 \mathrm{~m}$ & $1778^{*}$ \\
2 & Antimony(sb) & Sb-124 & $60.2 \mathrm{~d}$ & $602 ; 723 ; 1368 ; 1691^{*} ; 2091$ \\
3 & Arsenic(As) & As-76 & $26.32 \mathrm{~h}$ & $559^{*} ; 657 ;$ \\
4 & Barium(Ba) & Ba-131 & $11.8 \mathrm{~d}$ & $124 ; 216 ; 373 ; 496^{*}$ \\
5 & Calsium(Ca) & Ca-49 & $8.72 \mathrm{~m}$ & $3084^{*} ; 4072$ \\
6 & Cerium(Ce) & Ce-141 & $32.5 \mathrm{~d}$ & $145^{*}$ \\
7 & Cobalt(Co) & Co-60 & $5.27 \mathrm{y}$ & $1173^{*} ; 1332$ \\
8 & Copper(Cu) & Cu-64 & $12.7 \mathrm{~h}$ & $511 ; 1346^{*}$ \\
9 & Europium(Eu) & Eu-152 & $13.33 \mathrm{y}$ & $122 ; 344 ; 1408^{*}$ \\
10 & Iron(Fe) & Fe-59 & $44.5 \mathrm{~d}$ & $143 ; 192 ; 1099^{*} ; 1291$ \\
11 & Lanthanum(La) & La-140 & $40.27 \mathrm{~h}$ & $487 ; 751 ; 815 ; 868 ; 919925 ; 1596.21^{*}$ \\
12 & Magnesium(Mg) & Mg-27 & $9.46 \mathrm{~m}$ & $843 ; 1014 *$ \\
13 & Mangan(Mn) & Mn-56 & $2.58 \mathrm{~h}$ & $846,1810^{*}, 2113$ \\
14 & Scandium(Sc) & Sc-46 & $83.81 \mathrm{~d}$ & $889^{*} ; 1120$ \\
15 & Samarium(Sm) & Sm-153 & $46.27 \mathrm{~h}$ & $69^{*} ; 103$ \\
16 & Sodium(Na) & Na-24 & $14.96 \mathrm{~h}$ & $1368^{*} ; 2754$ \\
17 & Thorium(Th) & Pa-233 & $27.0 \mathrm{~d}$ & $312^{*}$ \\
18 & Tungsten(W) & W-187 & $23.9 \mathrm{~h}$ & $72 ; 134 ; 479^{*} ; 551 ; 618 ; 685 ; 772$ \\
19 & Vanadium(V) & V-52 & $3.75 \mathrm{~m}$ & $1434^{*}$ \\
20 & Zinc(Zn) & Zn-65 & $243.9 \mathrm{~d}$ & $1115^{*}$ \\
\hline
\end{tabular}

$\mathrm{h}=$ hour, $\mathrm{m}=$ minute, $\mathrm{d}=$ day, $\mathrm{y}=$ year.

A typical representative gamma-ray spectrum was taken from irradiated graphite leaching HF. The $(\mathrm{n}, \gamma)$ short-lived products were obtained from the 15 seconds long irradiated sample with a 5 minute cooling time, namely Mg-27, V-52, Al-28 and Ca-49 (Figure 3) and by extending the cooling time for 1 hour, the Mn-56 radionuclide was also obtained (Figure 4). The radiation of sample for the duration of 5 minutes with a 2 days cooling time yielded the six (6) medium-lived products such as Sm-153, W-187, As-76, Cu-64, Na-24 and La-140 (Figure 5). Finally, The radiation of sample for the duration of 30 minutes with a 1 week cooling time generated the ten (10) long-lived products, such as; Ce-141, Pa-233, Ba-131, Sc-46, Fe-59, Zn-65, Eu-152, La-140 and Sb-124 (Figure 6). This peak energy was used for quantitative analysis of element. Two methods are used to determine the concentration of an element in the sample; the first method is the comparator method for short live radionuclides and the Key-zero method for medium and long live radionuclides. 


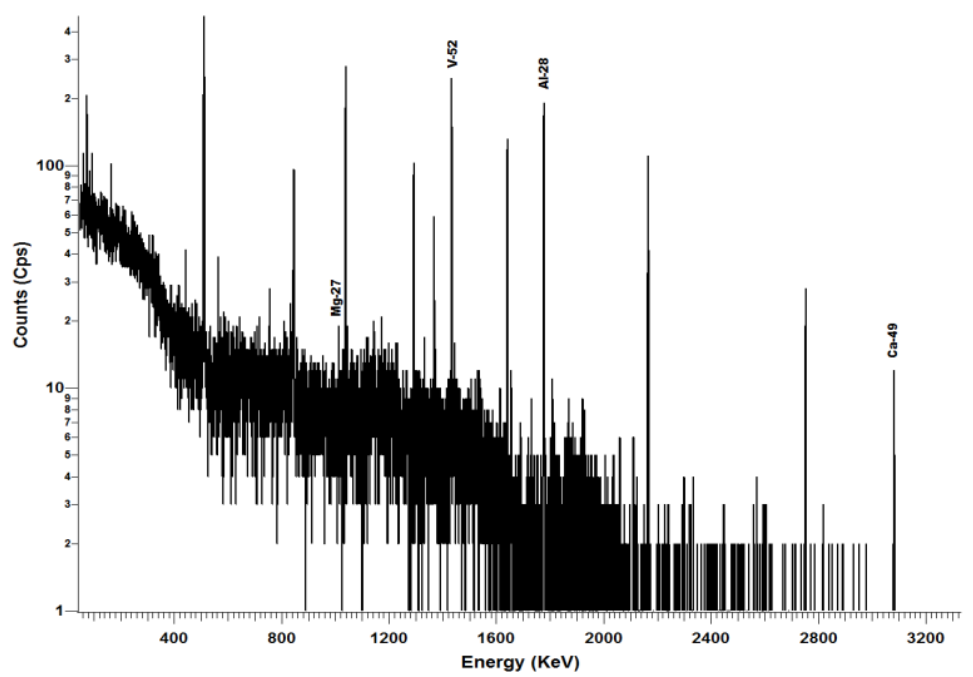

Figure 3. Gamma-ray spectrum of short neutron irradiation of graphite sample (15 second irradiation and 5 minute cooling time)

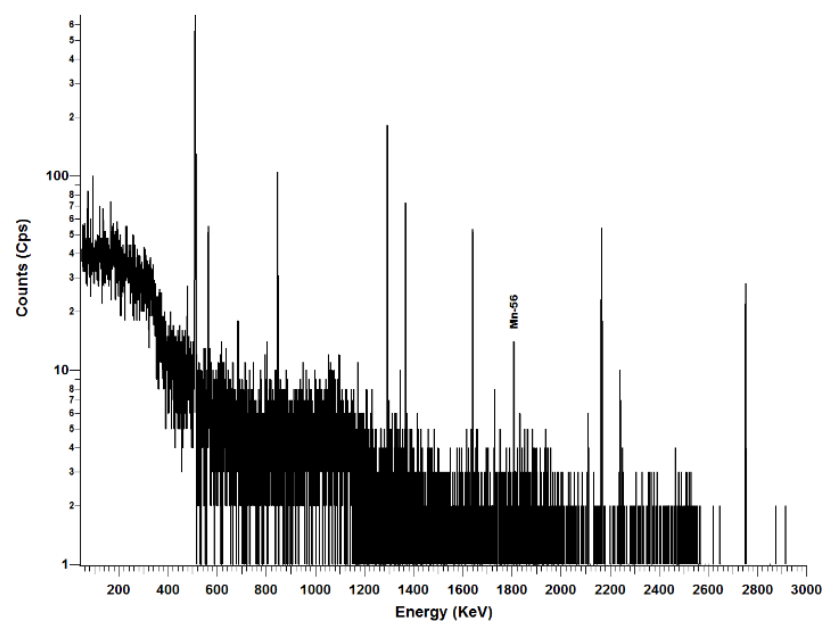

Figure 4. Gamma-ray spectrum of short neutron irradiation of the graphite sample (15-second irradiation and 1hour cooling time)

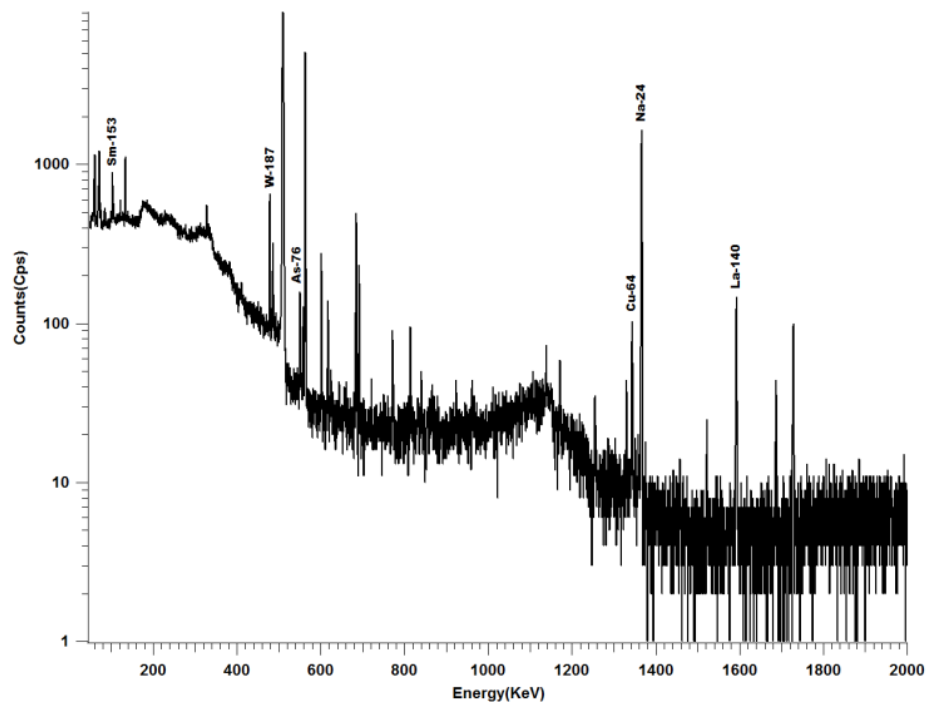

Figure 5. Gamma-ray spectrum of medium neutron irradiation of the graphite sample (5-minute irradiation and 2 days cooling time) 


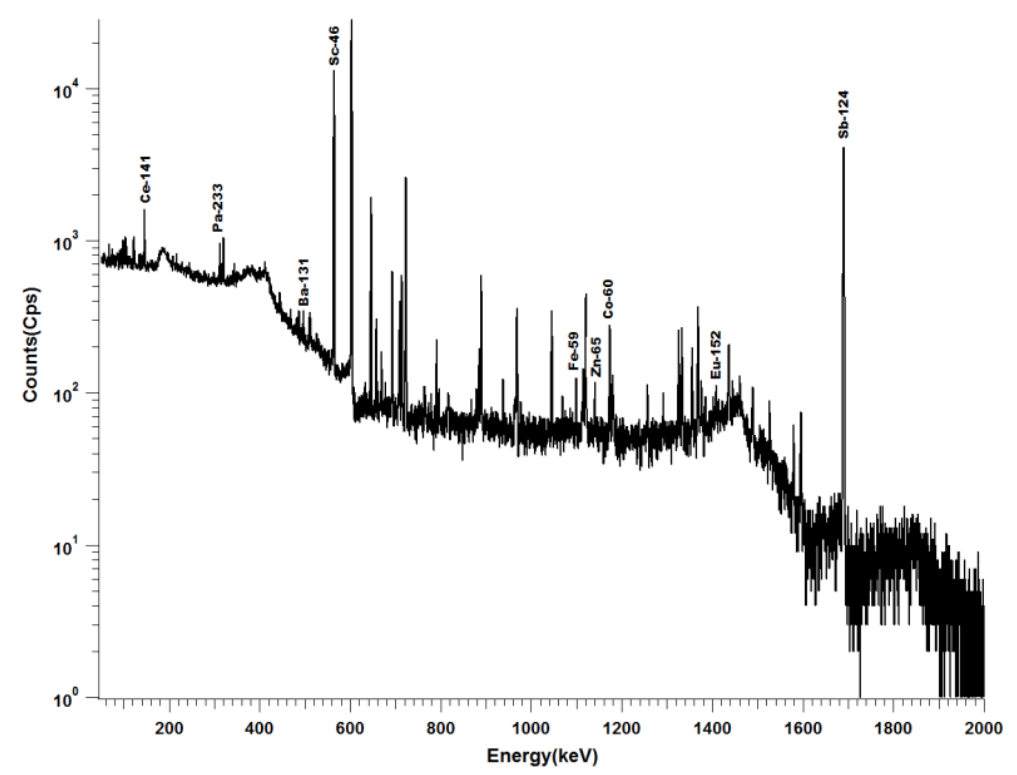

Figure 6. Gamma-ray spectrum of long neutron irradiation of the graphite sample (30-minute irradiation and 1 week cooling time)

Some elements have shown poor detection limits due to the mainly poor statistics of the integrated number of characteristic photo peaks. Limits differ from sample to sample because of the difference in concentration of the most active radionuclides. Twenty (20) elemental concentrations were determined in the analyzed sample using this NAA method. However, eleven (11) elements have been successfully verified in graphite (non treated acid) sample (Table 3). The concentration of impurities does indeed vary in graphite material, which can generally be divided into three groups, such as significant elemental content $(\mathrm{Cu}$ and $\mathrm{Sb}$ ), intermediate scale content ( $\mathrm{Al}, \mathrm{Na}, \mathrm{Zn})$ and in significant or minor content ( $\mathrm{Co}, \mathrm{La}, \mathrm{Mn}, \mathrm{Sc}, \mathrm{W}$, and V). The $\mathrm{Cu}$ elemental content is the most significant concentration in graphite with the value of $60,675 \mathrm{mg} / \mathrm{kg}$. This value is proportional to about $90 \%$ of the total impurities content in graphite. Followed by the $\mathrm{Sb}$ elemental content as the second most significant content, with a value of $5,514 \mathrm{mg} / \mathrm{kg}$ (about $8 \%$ of total impurities content in graphite). The remaining $2 \%$ includes the intermediate and the minor content of other impurity elements. The elemental concentration of $\mathrm{Al}, \mathrm{Zn}, \mathrm{Na}$ present in the graphite material were $741 \mathrm{mg} / \mathrm{kg}, 408 \mathrm{mg} / \mathrm{kg}$ and $171 \mathrm{mg} / \mathrm{kg}$, respectively. The trace other elemental concentration of elements such as $\mathrm{V}, \mathrm{W}, \mathrm{Mn}, \mathrm{Co}$, La, and Sc were $27.5 \mathrm{mg} / \mathrm{kg} ; 19.4 \mathrm{mg} / \mathrm{kg} ; 9.04 \mathrm{mg} / \mathrm{kg} ; 5.59 \mathrm{mg} / \mathrm{kg} ; 3.56 \mathrm{mg} / \mathrm{kg}$ and $0.28 \mathrm{mg} / \mathrm{kg}$, respectively. These results indicate that the recovery of graphite local Indonesia by froth floating process still produces graphite materials having a high concentration of impurities. Further, treatment was required to increase the purity grade of graphite.

The amount of impurities tends to decrease after the graphite was treated by acid reagents. The $\mathrm{Cu}$ and $\mathrm{Zn}$ element dissolved well for three types of used reagents, of which as much as $98 \%$ and $96 \%$ or higher could be removed respectively. Especially for the $\mathrm{Cu}$ element, it is encouraging due to the $\mathrm{Cu}$ element is the most significant impurity content in graphite. Consequently, the total impurities concentration drops drastically in the graphite. Sb element can be eliminated by as much as $98 \%$ (with about $93 \mathrm{mg} / \mathrm{kg}$ remaining) by employing a $\mathrm{HF}$ reagent. $\mathrm{However}_{2} \mathrm{HNO}_{3}+\mathrm{H}_{2} \mathrm{SO}_{4}$ and $\mathrm{HF}+\mathrm{HCl}+\mathrm{H}_{2} \mathrm{SO}_{4}$ are only able to dissolve the $\mathrm{Sb}$ element as much as $21 \%$ and $38 \%$ with concentration of 4,348 $\mathrm{mg} / \mathrm{kg}$ and 3,421 $\mathrm{mg} / \mathrm{kg}$ respectively remaining. Unfortunately, both the $\mathrm{Al}$ and $\mathrm{W}$ elements were difficult to dissolve in all three of the used reagents which are only able to remove about $14 \%$ of both elements. Sodium (Na) is very poorly dissolved in an $\mathrm{HF}$ reagent, but becomes easily dissolved in both $\mathrm{HNO}_{3}+\mathrm{H}_{2} \mathrm{SO}_{4}$ and $\mathrm{HF}+\mathrm{HCl}+\mathrm{H}_{2} \mathrm{SO} \mathrm{O}_{4}$ reagents. In addition, the other elements like $\mathrm{Co}, \mathrm{La}, \mathrm{Mn}, \mathrm{Sc}, \mathrm{V}$ which are trace impurities element in graphite decrease in concentration due to the treatment with acid reagent.

The total amount of concentration is $6.7 \%(67.575 \mathrm{mg} / \mathrm{kg})$ for the 11 elements determined by INAA. After the acid treatment, the amount of impurities' concentration decrease drastically to become $0.1 \%(1,047 \mathrm{mg} / \mathrm{kg}), 0.6 \%(6,045$ $\mathrm{mg} / \mathrm{kg}), 0.49 \%(4,920 \mathrm{mg} / \mathrm{kg})$ for $\mathrm{HF}, \mathrm{HNO}_{3}+\mathrm{H}_{2} \mathrm{SO}_{4}$ and $\mathrm{HF}+\mathrm{HCl}+\mathrm{H}_{2} \mathrm{SO}_{4}$ reagent, respectively. Cu element makes the largest contribution to reduce the concentration of impurities in graphite. The HF is the best of reagent due to the lowest of total impurities which are obtained the graphite close to in low purity grades for nuclear graphite $(1000 \mathrm{mg} / \mathrm{kg})$ (Windes et al. 2014). Several other elements like $\mathrm{As}, \mathrm{Ba}, \mathrm{Ca}, \mathrm{Ce}, \mathrm{Eu} \mathrm{Fe}, \mathrm{Mg}, \mathrm{Sm}$, and $\mathrm{Th}$ were also identified in the acid treatment sample but not identified in the non-treated acid sample. However, most of them are trace elements contains. We suspect that these elements are derived from the impurity of the used reagent and contamination during sample preparation (IAEA 1990). 
Table 3. The concentration of element in graphite and treated acid of graphite (unit (mg/kg)

\begin{tabular}{cccccc}
\hline \multirow{2}{*}{ No } & \multirow{2}{*}{ Element } & graphite & \multicolumn{3}{c}{ Treated } \\
\cline { 4 - 6 } & & & $\mathrm{HF}$ & $\mathrm{HNO}_{3}+\mathrm{H}_{2} \mathrm{SO}_{4}$ & $\mathrm{HF}+\mathrm{HCl}+\mathrm{H}_{2} \mathrm{SO}_{4}$ \\
\hline 1 & Aluminium(Al) & $695 \pm 4$ & $684 \pm 26$ & $696 \pm 17$ & $593 \pm 15$ \\
2 & Antimony(Sb) & $5,514 \pm 140$ & $93 \pm 2.4$ & $4,348 \pm 49$ & $3,421 \pm 37$ \\
3 & Cobalt(Co) & $5.59 \pm 0.47$ & $1.49 \pm 0.06$ & $4.13 \pm 0.2$ & $4.09 \pm 0.32$ \\
4 & Copper(Cu) & $60,675 \pm 2.14$ & $1,088 \pm 59$ & $925 \pm 58$ & $835 \pm 57$ \\
5 & Lanthanum(La) & $3.56 \pm 0.33$ & $3.09 \pm 0.16$ & $2.15 \pm 0.14$ & $2.27 \pm 0.16$ \\
6 & Mangan(Mn) & $9.04 \pm 0.38$ & $2.05 \pm 0.07$ & $2.7 \pm 0.07$ & $1.87 \pm 0.08$ \\
7 & Scandium(Sc) & $0.28 \pm 0.03$ & $0.14 \pm 0.01$ & nd & nd \\
8 & Sodium(Na) & $166 \pm 9$ & $170 \pm 8.8$ & $39.2 \pm 1.3$ & $29.4 \pm 1.19$ \\
9 & Tungsten(W) & $19.4 \pm 1.67$ & $16.59 \pm 0.63$ & $18.8 \pm 0.74$ & $19.14 \pm 0.78$ \\
10 & Vanadium(V) & $27.5 \pm 1.26$ & $15.09 \pm 0.54$ & $9.1 \pm 0.31$ & $14.6 \pm 0.51$ \\
11 & Zinc(Zn) & $408 \pm 34.7$ & $14.74 \pm 1.02$ & nd & nd \\
& Total & $\mathbf{6 7 , 5 7 5}$ & $\mathbf{1 , 0 4 7}$ & $\mathbf{6 , 0 4 5}$ & $\mathbf{4 , 9 2 0}$
\end{tabular}

\section{Conclusion}

The eleven (11) elements were successefully determined in forth floating process of an Indonesian local graphite sample. The $\mathrm{Cu}$ element was the most significant content with a value of $60,675 \mathrm{mg} / \mathrm{kg}(6 \% \mathrm{w} / \mathrm{w})$, followed in the second place by the $\mathrm{Sb}$ element with a value of $5,514 \mathrm{mg} / \mathrm{kg}(0.5 \% \mathrm{w} / \mathrm{w})$. Further, the content of $\mathrm{Al}, \mathrm{Na}$ and $\mathrm{Zn}$ element were hundreds mg/kg (741 mg/kg, $408 \mathrm{mg} / \mathrm{kg}$ and $171 \mathrm{mg} / \mathrm{kg}$ ), respectively. The other elements (V, W, Mn, Co, La, Sc) tracer were less than $27.5 \mathrm{mg} / \mathrm{kg}$. The concentration of most elements decrease after graphite was treated by a reagent acid. The total element contents can be removed above $91 \%$ in graphite with the various treated acid. The HF was the best reagent to eliminate the graphite impurities which results the graphite of low purity grades approach for nuclear application.

\section{Acknowledgment}

We would like to thank Ministry of Research, Technology and Higher Education (Indonesia) for funding this research through Insinas Flagship Program. We would also like to thank Dr. Geni Rina Sunaryo, M.Sc, Ir. Agus Sumaryanto, M.S.M, Ratih Langenati, M.Eng and Dr. Iwan Sumirat for the provision of facilities to accomplish the research. We are also grateful to our colleagues from Center for Nuclear Fuel Energy - National Nuclear Energy Agency (BATAN), Center for Science and Technology for advanced Material - National Nuclear Energy Agency (BATAN) for the assistance during the research.

\section{Reference}

Arachchi, W. A. S. M. W., Hewathilake, H. P. T. S., Senevirathna, T. C., Balasooriya, N. W. B., \& Wijayasinghe, H. W. M. A. C. (2017). A new chemical method for purification and surface modification of Sri Lankan Vein graphite. 7th Int. Symp. 2017(Intsym2017)-SEUSL. https://www.researchgate.net/publication/317604932

Chu, C. C., Chen, P. Y., Yang, M. H., \& Alfassi, Z. B. (1990). Determination of trace impurities in silicon and chlorosilines by inductively coupled plasma atomic emission spectrometry and neutron activation analysis. Analyst, 115, 29-34. https://doi.org/10.1039/an9901500029

Cruz, S. M., Schmidt, L., Nora, F. M. D., Pedrotti, M. F., Bizzi, C. A., Barin, J. S., \& Flores, E. M. M. (2015). Microwave-induced combustion method for the determination of trace and ultratrace element impurities in graphite samples by ICP-OES and ICP-MS. Microchem. J., 123, 28-32. https://doi.org/10.1016/j.microc.2015.05.008

Florena, F. F., Syarifuddin, F., Hanam, E. S., Trisko, N., Kustiyanto, E., Enilisiana, A. R., \& Arinton, G. (2016). Floatability study of graphite ore from southeast Sulawesi (Indonesia). AIP Conf. Proc., 1712, 50005. https://doi.org/10.1063/1.4941888

Ghosh, M., Swain, K. K., Devi, P. S. R., Chavan, T. A., Singh, A. K., Tiwari, M. K., \& Verma, R. (2017). Determination of impurities in graphite using synchrotron radiation based X-ray fluorescence spectrometry. Appl. Radiat. Isot., 128, 210-215. https://doi.org/10.1016/j.apradiso.2017.07.025

Hashitani, H., Izawa, K., Yoshida, H., \& Adachi, T. (1986). Spectrophotometric determination of traces of sulfur in 
graphite after wet oxidation decomposition. Bunseki Kagaku, 35, 916-919. https://doi.org/10.2116/bunsekikagaku.35.11_916

IAEA (1990). Practical Aspects of Operating a Neutron Activation Laboratory. IAEA-TECDOC-564, 1990. https://www-pub.iaea.org/MTCD/Publications/PDF/te_564_web.pdf

IAEA (2012). Advances in high temperature gas cooled reactor fuel tecnology-IAEA-Tecdoc-1674. IAEA. https://www-pub.iaea.org〉MTCD〉Publications>PDF>TE_1674_CD_web

Jerzy, J., \& Kwiecinska, B. (2015). Geochemical studies of natural graphites by INAA determined trace element concentration. J. Radioanal. Nucl. Chem., 305(1). https://doi.org/10.1007/s10967-015-4247-6

Joni, I. M., Camellia, P., Darmawan, H., Bambang, M. W., Anton, R., \& Husni, T. (2013). Synthesis and disperson of nanoparticles and Indonesian graphite processing. AIP Conference Proceedings, 1554, 20. https://doi.org/10.1063/1.4820275

Maahs H. G., \& Schryer, D. R. (1967). Chemical Impurity data on selected artificial graphites with comments on the catalytic effect of impurities on oxidation rate, Nasa Techn. Wasinton D.C: National Aeronautisc and Space Adminitration, 1967. https://ntrs.nasa.gov/archive/nasa/casi.ntrs.nasa.gov/19670030779.pdf

Mesko, M. F., Pereira, J. S. F., Moraes, D. P., Barin, J. S., Mello, P. A., Paniz, J. N. G., ... Flores, E. M. M. (2010). Focused microwave-induced combustion: a new technique for sample digestion. Analyical Chem., 82(5), 2155-2160. https://doi.org/10.1021/ac902976j

Mohammadzadeh, M., Ajami, M., Shadeghipanah, A., \& Rezvanifard, M. (2018). A study of neutron activation analysis compared to inductively coupled plasma atomic emission spectrometry for geological samples in Iran. Nucl. Eng. Technol., 1-6. https://doi.org/10.1016/j.net.2018.07.015

Mulyaningsih, T. R., \& Yusuf, S. (2018). Determination of minerals content in leaves of moringa oleifera by neutron activation analysis. Ganendra J. Nucl. Sci. Technol., 21(1), 11-16. https://doi.org/10.17146/gnd.2018.21.1.3683

Mustika, D. Torowati, T., Sudirman, S., Fisli, A., Joni, I. M., Langenati, R., \& Setiawan, J. (2019). Purification of Indonesian natural graphite by acid leaching method as nuclear fuel matrix: physical characterization. Int. J. Chem., 11(1), 9-17. https://doi.org/10.5539/ijc.v11n1p9

Natarajan, V., Porwal, N. K., Babu, Y., Rajeswari, B., Dhawale, B.A., Kumar, M., ...Manchanda, V. K. (2010). Direct determination of metallic impurities in graphite by EDXRF. Appl. Radiat. Isot., 68, 1128-1131. https://doi.org/10.1016/j.apradiso.2009.12.042

Obi, F. C. (1990). Use of X-ray fluorescence spectrometry to determine trace elements in graphite. Niger. J. Technol., 14(1), 1-4. https://www.ajol.info>index.php>njt>article>download

Pickhardt, C., \& Becker, J. S. (2001). Trace analysis of high-purity graphites by LA-ICP-MS. Fresenius J. Anal. Chem., 370, 534-540. https://doi.org/10.1007/s002160100873

Pierson, H. O. (1993). Handbook of Carbon, Graphite, Diamond and Fullerenes. Handb. Carbon, Graph. Diam. Fullerenes, 25-69. https://doi.org/10.1016/B978-0-8155-1339-1.50018-9

Robert, P. M. (2007). Purifying Coal for the production of nuclear graphite, (unpublished master's thesis), University Pretoria, South Africa. https://repository.up.ac.za/bitstream/handle/2263/24051/dissertation.pdf?sequence=1

Sadanandam, R., \& Sharma, A. K. (2016). Boron Equivalent For Nuclear Grade Natural Uranium-An Explanation Boron Equivalent For Nuclear Grade Natural Uranium, Retrived from. https://www.researchgate.net/publication/297386865

Santos, J. O., Munita, C. S.,Valério, M. E. G.,Vergne, C., \& Oliveira, P. M. S. (2006). Determination of trace elements in archaeological ceramics and application of Kernel Density Estimates: Implications for the definition of production locations. J. Radioanal. Nucl. Chem., 269(2), 441-445. https://doi.org/10.1007/s10967-006-0405-1

Schaffer, U., \& Krivan, V. (2001). Analysis of high purity graphite and silicon carbide by direct solid sampling electrothermal atomic absorption spectrometry. Fresenius J. Anal. Chem., 371, 859-860. https://doi.org/10.1007/s002160100971

Shinde, A. D., Acharya, R., \& Verma, R. (2012). Chemical characterization of graphite by instrumental neutron activation analysis Chemical characterization of graphite by instrumental neutron activation analysis. J. Radioanal. Nucl. Chem., 294, 409-412. https://doi.org/10.1007/s10967-011-1467-2

Sutisna, A., Suprapti, S., \& Istanto (2018). Elemental quantification of Wepal Sample under the 2017 IAEA Proficiency Test Program using Neutron Activation Analysis. International Conference on Materials Science \& Technology, 
Puspiptek Serpong, Indoensia, 13 December, 2018. http://repo-nkm.batan.go.id/8212/

Suzuki, H., Miyatani, T., \& Yoshimoto, O. (1993). Determination of impurities in graphite by ICP-MS and AAS using a metal furnace. Bunseki Kagaku, 42, 485-489. https://doi.org/10.2116/bunsekikagaku.42.8_485

Windes, W., Strydom, G., Smith, R., \& Kane, J. (2014). Role of nuclear grade graphite in controlling oxidation in modular HTGRs. INL/EXT-14-31720, ART Program, Idoha National Laboratory, U.S. Departement of Energy National Laboratory. https://doi.org/10.2172/1167529

Witkowska, E., Szczepaniak, K., \& Biziuk, M. (2005). Some applications of neutron activation analysis: A Review. J. Radioanal. Nucl. Chem., 265(1), 141-150. https://doi.org/10.1007/s10967-005-0799-1

Zacharia, A., Gucer, S., Izgi, B., Chebotarev, A., \& Karaaslan, H. (2007). Direct atomic absorption spectrometry determination of tin, lead, cadmium and zinc in high-purity graphite with flame furnace atomizer. Talanta, 72 , 825-830. https://doi.org/10.1016/j.talanta.2006.10.040

Zhou, X. W., Tang, Y. P., Lu, Z. M., Zhang, J., \& Liu, B. (2017). Nuclear graphite for high temperature gas-cooled reactors. New Carbon Mater., 32(3), 193-204. https://doi.org/10.1016/S1872-5805(17)60116-1

\section{Copyrights}

Copyright for this article is retained by the author(s), with first publication rights granted to the journal.

This is an open-access article distributed under the terms and conditions of the Creative Commons Attribution license (http://creativecommons.org/licenses/by/4.0/). 